\title{
VIDA, PALAVRAS E ALGUNS OUTROS TRAÇADOS: LENDO VEENA DAS
}

Adriana Vianna ${ }^{1}$

${ }^{1}$ Programa de Pós-graduação em Antropologia Social, Museu Nacional, Universidade Federal do Rio de Janeiro, RJ, Brasil

\section{Puxando o fio: chegando a Vida e Palavras}

A publicação de Vida e Palavras, de Veena Das, pela Editora da Unifesp, permite que tenhamos finalmente um livro completo em português desta que já se tornou uma referência fundamental na antropologia contemporânea e cujo trabalho vem deixando marcas importantes na formação e na produção acadêmica brasileiras. ${ }^{1}$ Até então, contávamos apenas com poucos artigos seus traduzidos para o português, alguns dos quais versões de textos que fazem parte de Vida e Palavras. ${ }^{2}$ Apesar da escassez de textos traduzidos, a influência de seu trabalho é notável em alguns campos de pesquisa no Brasil, contribuindo para delinear perspectivas de análise e inquietações metodológicas, bem como para firmar vocabulários imediatamente reconhecíveis.

Este é o caso, por exemplo, das discussões em torno das "margens do Estado", título de um seminário e subsequente coletânea organizados com Deborah Poole reunindo diversos pesquisadores, como Talal Asad, Pradeep Jeganathan e outros (Das \& Poole 2004), que têm forte presença em debates sobre as práticas de Estado em áreas periféricas e de favelas. Já o conjunto de reflexões sobre violência, subjetividade e sofrimento, materializado em coletâneas co-organizadas com pesquisadores como Arthur Kleinman, Margareth Lock, Pamela Reynolds e Manphela Ramphele, mas também em outros artigos e no próprio Vida e Palavras, contribuiu significativamente para o delineamento de um perímetro em torno do sofrimento e da dor como 
temas de investigação antropológica. ${ }^{3}$ O modo como "eventos críticos", termo que dá título a seu livro de 1995, rompem a vida cotidiana e obrigam à busca por caminhos para recriá-la, por sua vez, trouxe todo um universo de questões sobre formas de gestão coletiva e pessoal do sofrimento, os regimes de linguagem possíveis de serem confeccionados para tanto e, em um tema que só ganha pleno contorno em Vida e Palavras, as relações entre os eventos e o cotidiano, bem como entre o extraordinário e o ordinário.

De modo geral, podemos dizer que os trabalhos de Das começam a nos chegar, ao menos em nível de pós-graduação, de maneira bem próxima das suas publicações, a partir de meados dos anos 1990 - ou seja, sobretudo a partir da publicação de Critical Events, em 1995, e da primeira das coletâneas que co-organizou sobre sofrimento social, violência e subjetividade. ${ }^{4}$ Sua presença como conferencista no XXII Encontro Anual da Anpocs, em 1998, seguramente contribuiu para torná-la mais conhecida no universo acadêmico brasileiro, especialmente com a publicação no ano seguinte de sua conferência na Revista Brasileira de Ciências Sociais, com o título de "Fronteiras, Violência e o Trabalho do Tempo: alguns temas wittgensteinianos" (Das 1999). Ao apresentá-la ao público, Mariza Peirano chamou a atenção para a importância do diálogo que a presença de Das nos traria, afinando-se com a preocupação já manifesta por Das com a pluralização da antropologia, tema a que, como sabemos, Peirano se dedicou em outros momentos com bastante densidade e reflexividade. ${ }^{5}$

Embora não vá seguir este caminho ao longo do ensaio, gostaria de deixar sublinhada aqui a possibilidade deste diálogo - ou reverberação ter papel de fato relevante no modo como muitos de nós na antropologia brasileira nos sentimos tocados, provocados e inspirados pelo trabalho de Das. Se esta não é, decerto, uma peculiaridade brasileira, haja vista o grande prestígio internacional da autora, tampouco me parece que deva ser tomada apenas como um afã de consumo de "grandes referências globais". Para além das questões colocadas por Peirano sobre as eventuais proximidades e diferenças entre as antropologias brasileira e indiana e suas relações com a centralidade euro-americana, a forma como violência, cotidiano, Estado, sofrimento e moralidades, para mencionar apenas alguns tópicos, vão sendo etnograficamente tecidos em seus textos encontra afinidades com muitas frentes de pesquisa e reflexões teóricas, metodológicas e ético-políticas de antropólogos e antropólogas nacionais. ${ }^{6}$

A publicação de Life and Words, em 2007, aprofunda e redefine noções que haviam aparecido em Critical Events, ao mesmo tempo em que traz novas perspectivas, algumas das quais já vinham sendo desenhadas nos trabalhos produzidos entre os dois livros. Como a própria autora explicitou em 
entrevista concedida a pesquisadores brasileiros em 2012, uma das diferenças fundamentais entre os dois livros é o amadurecimento de suas reflexões sobre as relações entre evento e cotidiano ou, mais precisamente, sobre como o evento ancora-se no cotidiano. ${ }^{7}$ Estas formulações são indissociáveis do modo como compreende tanto a violência quanto o tempo no livro, mas também, eu diria, da forma como a dimensão ética ou mesmo espiritual da etnografia é afirmada não só neste trabalho, mas em textos posteriores.

No Brasil, o livro é recebido com algumas resenhas em periódicos acadêmicos (Vieira 2010; Pereira 2010). A publicação alguns anos mais tarde de um de seus capítulos nos cadernos pagu amplia a circulação de seu trabalho, sobretudo no multifacetado campo dos estudos de gênero (Das 2011). Paralelamente, circulam algumas traduções em língua espanhola que possibilitam, em cursos de pós-graduação e de graduação, acesso mais amplo para quem não domina a leitura em inglês (Das 2008a, 2008b). O impacto dos textos e o modo como foram sendo absorvidos, transmitidos e digeridos por pesquisadores formados ou em formação exigem uma investigação que, infelizmente, não tenho como apresentar no momento. Atenho-me a registrar, mesmo que de maneira quase impressionista, que a presença de certa terminologia tão característica e tão central em sua obra, e em especial em Vida e Palavras, foi se tornando crescentemente familiar entre nós na última década. Contribuíram para tanto, sem dúvida, além das traduções já mencionadas, dossiês inspirados em temáticas que têm seus textos como referência, e programas de curso de graduação e pós-graduação. ${ }^{8}$

A perspectiva analítica de tomar a violência não a partir de seu movimento ascendente, mas de sua "descida ao ordinário" e as diversas refrações nela presentes - em relação a sujeito, voz, devastação, cura, expressão e tempo, entre outras - têm, certamente, papel de destaque na capacidade inspiradora de que o livro vem demonstrando ser capaz. Como são muitos os caminhos possíveis para falar sobre ou a partir dele, escolhi neste ensaio realizar dois movimentos. No primeiro, ofereço uma leitura do próprio livro, sublinhando alguns pontos que considero marcantes em sua abordagem. Em seguida, procuro indicar brevemente algumas questões, reflexões e sensibilidades presentes no livro que foram sendo reiteradas e amplificadas em textos posteriores. Desnecessário dizer que os pontos que trago aqui nem de longe dão ideia da diversidade e da complexidade de discussões que a autora vem enfrentando em sua vasta e intensa produção, tanto individual quanto em parcerias e circuitos de estreita troca intelectual.

Em recente coletânea estruturada justamente em torno das apropriações e dos diálogos que uma geração mais jovem de antropólogos(as) estabeleceu com a obra de Das, Roma Chatterji chama a atenção para a variedade de 
temas que o conjunto de artigos foi capaz de trazer (Chatterji 2015:01-2). Tomando como marcas principais do trabalho de Das as reflexões sobre as bases éticas para escrever e pensar sobre a dor alheia, as relações entre evento e experiência ordinária cotidiana e a natureza e as implicações éticas do conhecimento antropológico, os dezoito artigos da coletânea distribuem-se entre etnografias diversas que abordam o tema da dor e do sofrimento social; das relações entre evento, cotidiano e violência; das relações entre ética e estética das relações; e da afinidade entre antropologia e arte como formas de descortinar mundos específicos. Em capítulo próprio ao final do livro, significativamente chamado por ela de "Adjacent Thinking: A Postscript", Das, por sua vez, diz que gosta de conceber sua forma de pensar como semelhante a movimentos de caranguejo, sem um começo ou um fim claramente definido, de modo que suas coordenadas são mais facilmente dadas por sua localização em um campo específico de conversas (Das 2015a:372). De maneira distinta de outras parcerias, porém, ao ver-se a partir dos olhos destas novas gerações, ela acaba por registrar a presença de nova camada do tempo, a do futuro que se imiscui no presente e convida à confiança de abandonar-se ao outro. O tempo, este tema tão caro em sua reflexão, não deixa de comparecer aqui, entremeado com outra dimensão presente em Vida e Palavras e sobre a qual também tentarei discorrer mais adiante: a das conexões entre etnografia e autobiografia.

\section{Um olhar sobre Vida e Palavras}

No parágrafo final do livro, ao explicitar como vê o papel público da antropologia, Das menciona, em pé de igualdade, o trabalho necessário de contradizer a amnésia oficial e o de testemunhar a descida ao cotidiano que permite que vítimas e sobreviventes afirmem a possibilidade da vida. Esta, por sua vez, seria indissociável do esforço de "dar um lar às palavras", exercício espiritual feito por suas interlocutoras, como Manjit, e também por filósofos como Cavell, com quem Das reitera seu sentimento de dívida. Como ela retoma em alguns textos posteriores, este final, que alinhava o valor das palavras de ambos conteria certo potencial "escandaloso" (Das 2012:139; Das 2015b:01). Uma vez que alguns dos sentidos possíveis para isto serão retomados na parte seguinte deste ensaio, contento-me aqui em notar que a escolha por terminar o livro afirmando esta conexão entre palavras distintas, mas também entre as vidas que com elas se entrelaçam, guarda ainda a força de definição da antropologia que a autora afirma como sua. Ou, como prefere ela, o seu "modo antropológico de devoção ao mundo". 
Conectar palavras e vidas, exercício espiritual, devoção. A este conjunto de termos poderíamos agregar outros igualmente interpeladores por seu papel analítico-expressivo: conhecimento venenoso, trabalho do tempo, sentir a dor no corpo do outro. Estas marcas de escrita respondem, entre outros apelos, à sua busca por produzir uma forma de compreender a violência que, pautada pelos contextos etnográficos desenhados em suas pesquisas, privilegia o trabalho de tornar a vida novamente possível por e para aquelas que foram diretamente atingidas por violências que escapam a uma definição familiar ou domesticada. Esta mudança na direção do olhar em relação aos eventos violentos traz um ganho analítico significativo, cujos desdobramentos vão se revelando ao longo dos capítulos. Para além destes ganhos, porém, ela expressa o compromisso da autora com suas interlocutoras que buscam, antes de tudo, tecer um cotidiano viável para si e para outros. Recusar as "narrativas congeladas" sobre a violência ou o sofrimento, evitar as perguntas que as induzam, abrir-se aos gestos, silêncios e elipse são, deste modo, mais que uma estratégia investigativa. Trata-se, como ela afirma neste mesmo capítulo final a que fiz menção, de entender que o modo antropológico de conhecer o sujeito se define em termos das condições sob as quais se torna possível falar da experiência.

Experiência e limite são, assim, indissociáveis da própria concepção de sujeito e subjetividade. A noção de que o sujeito, longe de pertencer ao mundo, é em verdade seu limite, extraída de Wittgenstein e apresentada por Das no primeiro capítulo do livro, coloca importantes reflexões sobre como considerar experiências de violência e sua capacidade de reconfigurar mundos, mas também sobre agência e voz como elementos centrais na figuração do sujeito. A presença de Wittgenstein e Cavell serpenteia esta compreensão de ponta a ponta, como ela mesma não deixa de notar em diversas passagens do livro e em outros textos. ${ }^{9}$ É em boa medida no diálogo com os trabalhos destes dois filósofos que Das encontra um caminho para ultrapassar a associação entre voz e discurso, por um lado, e para localizar o cotidiano no centro de sua reflexão, por outro. Se a voz, afinal, é aquilo que infunde vida e alma às palavras e se isto só se realiza no contato direto com a experiência cotidiana, persegui-la etnograficamente implica uma série de cuidados e sensibilidades que contrariam modelos já bastante sedimentados de pesquisas sobre eventos violentos.

A percepção da violência como categoria fundamentalmente instável e não transparente, ${ }^{10}$ por sua vez, faz com que esta jamais seja apresentada como um campo evidente, algo a que leitores poderiam ser facilmente induzidos pela própria natureza dos eventos que referenciam as duas grandes empreitadas etnográficas que dão corpo ao livro. Ao invés disto, a violência 
apresenta-se em diferentes matizes, refratando-se e diferenciando-se, convocando gêneros narrativos e recursos expressivos distintos. O desconforto que Das explicita em relação a tentativas anteriores de escrever um livro que tivesse em seu centro o tema da violência dialoga com essa multiplicidade, mas também com o contraste entre as narrativas midiáticas e estatais e o que ela percebia junto àquelas e àqueles que viveram e seguiam vivendo, de algum modo, efeitos de experiências brutais. Se uso aqui o verbo perceber, é em uma tentativa de respeitar o modo como Das parece fazer questão de nos introduzir às suas reflexões sobre o tema deixando marcado algo do processo de estranheza e de sensibilização inerentes a seu modo de fazer etnografia. ${ }^{11}$ Do mesmo modo que defende os fragmentos como recursos heurísticos que recusam a ilusão da totalidade e aludem a uma forma enlutada de habitar o mundo, sua escrita parece querer honrar os componentes de atordoamento e incômodo que, mais que os corpus conceituais estáveis, permitem passagens para a compreensão sensível da dor do outro.

O fato de o livro assentar-se em dois trabalhos de campos distintos obriga e favorece a explicitação das conexões sociais e analíticas entre as situações trazidas. O primeiro deles, em torno do qual se organizam os capítulos 2 a 5, concentra-se em mulheres hindus que sobreviveram aos eventos violentos relacionados à Partição da Índia, em 1947. O segundo, que responde pelos capítulos 7 a 10, tem início em uma área periférica de Delhi logo após os massacres de pessoas sikhs, homens em sua maioria, em reação ao assassinato, em 1984, da então primeira-ministra Indira Gandhi por seus guarda-costas. O capítulo 6, por sua vez, desempenha o papel de uma dobra - ou ponte, nos termos da autora - entre os campos, dedicando-se com especial atenção às relações entre tempo e subjetividade, enquanto o capítulo final, o 11, com o qual iniciei os comentários desta parte do ensaio, volta-se aos temas do trauma e do testemunho, bem como da responsabilidade antropológica.

Retornando à violência - ou à sua não transparência - como o fio que é tensionado pela perspectiva centrada na voz e no cotidiano, há mais alguns pontos marcantes de sua abordagem que gostaria de destacar. $\mathrm{O}$ primeiro deles diz respeito aos múltiplos e possíveis desafios de acessar o que se considera o evento violento e sua memória em meio a relações de proximidade ou intimidade. No caso das mulheres sobreviventes da Partição, esta memória estava emaranhada em relações familiares e naquilo que Das descreve como uma estética do parentesco atravessada por menções e referências nem sempre explícitas a favores, traições, dívidas e queixas. Já no caso das mulheres sikhs que viram seus maridos e filhos serem massacrados por vizinhos e conhecidos, a memória, embora literalmente materializada nas marcas ensanguentadas e carbonizadas 
nas paredes, permanecia de algum modo obscurecida. Em ambas as situações, um mesmo vetor: a ambivalência da vida em comum - a forma de vida compartilhada - como aquilo que tanto pode ferir de modo mais dramático, justo pela proximidade e pelo compartilhamento, quanto pode curar, no processo sempre delicado e precário de reconfecção do cotidiano. Na intimidade agonística do cotidiano, ordinário e extraordinário se encontram, entramados um ao outro (Das 2010a:02).

Se neste contexto as palavras podem, como já mencionado, quedar-se congeladas ou guardar venenos que destruiriam o tecido das relações e dos afetos, sua confiabilidade tem que ser recalibrada na pesquisa. Ou, quem sabe, colocada de ponta-cabeça, na medida em que sua força surge de momentos especialmente intrigantes ou pungentes, como na mulher moribunda que não quer que sua mortalha venha da casa do irmão; nas mulheres que se mantêm sujas e desgrenhadas, ostentando através de seus corpos a marca da devastação trazida pelo massacre, mas também expressando a força do mito da conspurcação de Draupadi, no Mahabharata; ou mesmo na situação limite em que a impossibilidade de retecer um cotidiano viável leva uma mãe que havia se suicidado a retornar para as filhas apenas sob a forma de fantasma.

A ênfase nestes e em outros casos não está necessariamente em dizer, mas em mostrar. Não em representar, mas em expressar. Não em falar ou descrever, mas em calar ou desfiar alegorias. Estamos longe, bem longe, portanto, de uma concepção de agência que se fixe ou se veja especialmente atraída pelas formas mais estrondosas de uma "resistência ativa". A agência, em um mundo devastado no qual corpos generificados configuram signos privilegiados para a constituição de imagens nacionais ou comunais, pode passar pela espera paciente, pelo silêncio, pela gestão de tensões e conflitos cotidianos. Assim procedem Asha e Manjit, suas interlocutoras, buscando fazer com que o trabalho do tempo as favoreça, que cure relações, ao invés de destruí-las, como bem sabem que é possível.

O tempo é dotado, ele mesmo, portanto, de capacidade de criar, de fazer nascer ou desmoronar mundos. Ao formular o tempo como trabalho, Das procura direcionar seu interesse não para as concepções ou as imaginações de tempo, mas para sua presença ativa nos processos e nas histórias que fazem as vidas. ${ }^{12}$ Isto permite conectar de outras formas a presença da violência em cada um dos seus trabalhos de campo, ao considerar a significativa diferença do trabalho do tempo neles, bem como perceber de que formas as histórias inacabadas de que o social é feito podiam surgir em um ou no outro. ${ }^{13}$ Uma demonstração exemplar e perturbadora desse ressurgimento do inacabado em sua máxima letalidade é fornecida pela análise dos rumores. 
Compreendido enquanto uma região específica da linguagem, o rumor permite atualizar imagens aterrorizantes e fantasmagóricas em novos eventos. Os rumores, explorados rigorosa e sistematicamente no cap. 7, que começam a circular logo após o assassinato de Indira Gandhi, extraem sua credibilidade de momentos passados, especialmente dos eventos da Partição. Mobilizando imagens como as de trens repletos de corpos, de planos para envenenar os reservatórios de água da cidade ou de grandes celebrações nas ruas pelo assassinato, dialogam com experiências de outro momento conturbado, não importa se de fato vividas ou apenas imaginadas. Para pensar a agência dessa forma específica de penetração do passado, Das tanto vai discutir, a partir de Bergson, propriedades próprias dessas transmissões e recriações do passado, as translações e as rotações, como vai procurar mostrar como se constitui a materialidade efetiva do rumor: como ele circula, que propriedades fundamentais carrega, sua força perlocutória, seus agentes, sua distribuição espacial, a quem pode atingir letalmente, quem deve poupar. Como também faz no caso da Partição, ao analisar meticulosamente a correlação entre a construção do Estado Nacional Indiano e os raptos e as "devoluções" de mulheres, Das mescla a análise delicada de elementos aparentemente difusos ou simbólicos com a materialidade etnográfica e sociológica que os coloca em direta relação com pessoas concretas, com projetos políticos, com disputas de poder.

É aqui que percebemos também uma das singularidades políticas de suas etnografias. Seja mostrando o fetiche da troca de mulheres como fenômeno de construção de um Estado nacional altamente generificado, em que a representação mitológica moderna do contrato social obscurece a força do contrato sexual que o atravessa, seja revelando a fabricação dos massacres aparentemente anônimos e frutos de ira coletiva como parte de disputas políticas bastante concretas tanto em nível nacional quanto local, Das desloca, inverte e desafia formas de enquadramento da realidade que são elas mesmas poderosos agentes de criação e moldagem do real. É assim que, ao adentrarmos com ela os blocos populares em Sultanpuri, localidade altamente atingida pelos massacres de 1984, passamos a ver, entre os capítulos 8 e 10, como a dinâmica dos assassinatos diz respeito a um complexo tecido social que inclui castas, etnias, relações de gênero e a ação de agentes de Estado como policiais, burocratas e políticos, além de mediadores locais. Descer ao ordinário aqui significa alterar os termos socioespaciais em que evento e cotidiano se relacionam a partir da imersão no local. As mortes brutais ganham, assim, padrão e ordem surpreendentes, lembrando-nos que um dos desdobramentos de etnografias densamente constituídas é a possibilidade de desfazer e recompor as formas mais usuais de compreensão de eventos de grande repercussão política. 
Ainda nesse conjunto de capítulos escritos centrados no trabalho de campo realizado entre 1984 e 1985, vale destacar a presença de outro tema importante na reflexão de Das e que é, como mencionei anteriormente, por certo, um dos mais conhecidos nas apropriações que vêm sendo feitas de sua obra no Brasil. Trata-se da natureza do Estado e de suas margens, bem como as porosas fronteiras entre legal e ilegal. Embora este tema, trazido sobretudo em razão da discussão sobre a ilegibilidade do Estado, seja destacado com mais evidência apenas no capítulo 9, ele pode ser rastreado ao longo de todo o livro, seja no modo como censos e categorias são estabelecidos em torno das mulheres e crianças raptadas na Partição, seja na forma como políticas de acesso a casas para populações pobres e marginalizadas relacionam-se a biopolíticas de controle da natalidade, ou ainda no modo como os direitos das viúvas são definidos tanto legalmente quanto culturalmente.

Cada um dos dois trabalhos de campo que fundamentam o livro demandou formas de engajamento diferentes, o que não apenas impactou as reflexões sobre violência e tempo, já indicadas aqui, mas também colocou em relevo aspectos distintos da sua responsabilidade enquanto antropóloga. As marcas destas condições são registradas ora de maneira explícita, como quando descreve o projeto coletivo e institucional que define sua entrada na área recentemente devastada pelos massacres em 1984, ora vislumbrada na intimidade que vai sendo criada no longo tempo de contato com suas interlocutoras. Em ambos os casos, seu engajamento não desconhece a centralidade da vida cotidiana como aquilo que, de um modo ou outro, fundamenta a busca por um mundo habitável. Não à toa, quando instada a responder sobre o lugar da política em sua vida, Das retoma a expressão final do livro, que fala de sua devoção ao mundo, para dizer que é na relação coletiva com seus estudantes, mas também na pesquisa como modo de responder ao que o mundo demanda de nós, que ela encontra o sentido propriamente político de seu trabalho (Das 2010b:141). Na parte que se segue, busco desdobrar algo deste fio a partir de alguns apontamentos sobre ética e etnografia em Vida e Palavras e alguns textos subsequentes.

\section{Seguindo o fio: breves indicações sobre ética e etnografia}

É apenas no capítulo final de Vida e Palavras que o tema da ética é colocado em destaque, mais precisamente a partir de uma discussão sobre a ética de responsabilidade. Em uma passagem significativa, Das declara que compreende "o corpo do texto antropológico como aquele que recusa cumplicidade com a violência ao se abrir à dor do outro" (Das 2020a:268). 
Em diversos momentos do livro, no entanto, esta recusa da cumplicidade com a violência através do trabalho de reconhecimento e abertura à dor é indicada, sem que respostas simples ou regras de conduta preestabelecidas possam ser oferecidas de maneira rígida e confortadora. O modo como Das recorre, no capítulo 3, "Linguagem e Corpo", à formulação de Wittgenstein sobre o jogo de linguagem talvez seja o que melhor expressa a incompletude e o risco inerentes a esse processo de abrir-se ao sofrimento alheio. Trago aqui um pouco mais longamente suas próprias palavras:

Nesse movimento entre corpos, a sentença "sinto dor" torna-se o canal pelo qual posso sair da inexprimível privacidade e asfixia da minha dor. Isso não significa que eu seja compreendida. Wittgenstein usa o caminho de uma gramática filosófica para dizer que essa não é uma afirmação indicativa, embora possa ter a aparência formal de uma. É o começo de um jogo de linguagem. A dor nessa interpretação não é aquela coisa inexprimível que destrói a comunicação ou marca uma saída da existência da pessoa na linguagem. Em vez disso, ela faz uma reivindicação ao outro - pedindo reconhecimento que pode ser dado ou negado (:60).

Tomar parte no jogo de linguagem é, desta forma, um compromisso ativo com o processo de reconhecimento demandado por aquele que sofre. Longe de ser algo imediato ou que tenha uma forma estável e predefinida, este reconhecimento precisa ser confeccionado na relação, oferecendo um lar à dor do outro (:80). Em um primeiro momento, parece mais imediato identificar esta formulação nos cuidados a serem adotados nos processos de pesquisa de campo, atentando para as possibilidades de participação em tramas violentas de toda ordem, como já indicado na parte anterior. Para além disto, porém, gostaria de sugerir desdobramentos que se relacionam à questão da ética, mas por ângulos diferentes.

O primeiro deles diz respeito a como a linguagem carrega, ela própria, a marca de um trabalho ético feito no plano do ordinário. A questão relevante, neste sentido, não seria simplesmente a de como alguém narra um evento, e sim como as palavras e os gestos cotidianos estão inseridos em formas de reconhecer ou não o outro em meio a uma trama de atos e práticas. A linguagem em si mesma, portanto, expressa e configura compromissos éticos presentes no dia a dia ao preservar ou arriscar a dignidade e a honra daqueles que estão em relação (Das 2012:136). A sustentação de uma posição viável nas redes familiares ou de vizinhança, a busca por modos de acomodar situações material e simbolicamente danosas, bem como o acúmulo de mágoas e desapontamentos não se realizam apenas em momentos dramáticos ou disruptivos, mas nesse gotejar das miudezas diárias. Esta forma de ver a ética está evidentemente afinada com toda a discussão sobre a perspectiva analítica voltada à descida da violência, tão marcante em Vida e Palavras. 
O giro mais explícito em relação à ética ordinária acontece, porém, um pouco depois. A coletânea Ordinary Ethics: Anthropology, Language and Action, organizada em 2010 por Michael Lambek, resultado de um workshop ocorrido em 2008, é sem dúvida um marco deste giro. Como coloca Lambek na Introdução, o livro reúne pesquisadores que vinham, por caminhos próprios, enfrentando o diálogo com perspectivas filosóficas acerca do lugar da ética na vida humana, mas com uma preocupação notadamente etnográfica (2010:05). Além do capítulo que assina no livro (Das 2010c), Das volta ao tema em uma sequência de textos posteriores $(2012,2015 b$, 2018). Um dos pontos que vai sublinhar é que a dimensão mais dramática da expressão de valores, aquilo que teria força ilocucionária, nos termos de Austin (1962), só pode ser plenamente sentido em sua correção ou veracidade quando integrada ao fluxo da vida cotidiana (Das 2012:140). Nesse sentido, falar de ética ordinária não é falar da obediência às regras formais ou da recitação moral, mas de um processo mais sinuoso e exigente, no qual, uma vez mais, o tempo tem papel decisivo, bem como a capacidade de confrontar-se continuamente com o desastre.

Para compreender as implicações disto, é fundamental manter em mente que o cotidiano é volátil, e não estático. A recusa de Das em enrijecer o cotidiano em uma plêiade de repetições e hábitos automatizados se manifesta uma vez mais aqui. Se, afinal, os atos e as experiências dramáticas podem por vezes parecer autonomizar-se da vida comum, colocando em risco inclusive o reconhecimento das formas de vidas, como tão bem marcado em Vidas e Palavras, é no trabalho de buscar um cotidiano vivível que a força danosa dessas experiências dramáticas pode ser reconfigurada, seja para que lado for. Longe de formar um vocabulário específico, portanto, a ética ordinária trata fundamentalmente do trabalho dos sujeitos para criar este cotidiano habitável, o que envolve a busca por conduzir-se corretamente em situações que são sempre incontornavelmente angustiantes. Não à toa, para precisar com mais clareza sua perspectiva sobre a ética ordinária, Das retoma situações de campo, repensando-as. Assim, voltamos a nos encontrar com a habilidade de Manjit para não melindrar a cunhada em uma situação de fragilidade econômica (Das 2018); com o drama de Billu, seu interlocutor em Affliction, e suas escolhas penosas em um mundo de imensa precariedade material (Das 2015d); mas também com Sita, a mulher que não queria ser enterrada com a mortalha proveniente da casa do irmão (Das 2020a, 2018).

Detenho-me neste último episódio brevemente mencionado no primeiro capítulo de Vida e Palavras e na forma como Das vai reconsiderá-lo - e, portanto, reconsiderar a si mesma - anos mais tarde. Em artigo recente, ela nos conta como, através da longa relação que manteve com a família de Sita, 
iniciada nos anos 1970, foi ganhando outro entendimento desta situação, em si tão dramática em termos das relações de parentesco (Das 2018:538-541). As histórias de ressentimento que se encontram entrelaçadas na textura das relações, para usar seus termos, desenham e vão sendo desenhadas em uma estética própria, em que têm lugar expressões de queixa e amor. A intensidade da mágoa revelada por Sita ao recusar a mortalha, porém, mostra que nem sempre o modo e o ritmo com que os desapontamentos são veiculados dão conta das operações que de fato estão em curso. Neste caso, as rotinas e os hábitos familiares ocultaram da pesquisadora, que julgava ser próxima da família, o quanto as relações de fato se esgarçavam. Talvez sua própria juventude na época e o tempo compartilhado não fossem fatores que afiançassem a confiança necessária para que as mágoas mostrassem sua profundidade. Mas, e este é um belo e surpreendente movimento no artigo, talvez fosse de sua própria experiência familiar que precisasse vir outro elemento para a compreensão dessas surpresas que os momentos liminares, como os do adoecimento e morte, guardam.

Um drama enfrentado no processo de doença de sua sogra a leva a reagir de acordo com o que pensa ser o correto em face dos desejos surpreendentes expressos na UTI por sua sogra, levando em conta o que ela, em sua longa relação como nora, podia engendrar como alternativa. Em uma pequena nota de rodapé, Das expressa tanto dúvidas sobre ser capaz de compreender plenamente suas próprias ações quanto o reconhecimento de que agira ali de maneira algo semelhante a como havia agido em diversas situações em campo (:540). A passagem, extremamente rica como é, aponta, entre outras coisas, para o caráter de profunda incerteza que atravessa a vida cotidiana, enquanto os acordos que a sustentam demonstram ser muito frágeis. Lidar com esta incerteza torna-se matéria de ética ordinária justo na medida em que, para manter nosso sentido da vida como um todo, precisamos encontrar maneiras de contornar tais desapontamentos (:541). Para fazê-lo, é preciso navegar de algum modo pela miríade dos hábitos, rotinas, afetos e desafetos compartilhados, imaginando possibilidades e arranjos que não traiam completamente a relação ou a forma de vida que se busca preservar.

Retornando um pouco a Vida e Palavras, em especial a seu parágrafo final, podemos ver que este é também o movimento que ela reconhece em suas interlocutoras. Em textos posteriores, Das retoma invariavelmente este parágrafo final e aquilo que nele traria algo de escandaloso, a saber, a localização em suas interlocutoras dos exercícios espirituais, normalmente associados, a partir de certa tradição filosófica, a um processo de elevação moral. ${ }^{14}$ Como ela reitera, seu objetivo aqui era justamente resgatar a expressão do domínio formal da filosofia para as "pequenas disciplinas" que as pessoas empreendem cotidianamente, entendendo-as como uma 
expressão da ética que permite sustentar a vida como um todo. Aprender com Manjit sobre que violências são ou não pronunciáveis, quais palavras estão entorpecidas, a importância moral de recusar a representação de certas violações sofridas e o envolvimento perene com o conhecimento venenoso que elas produziam são alguns dos pontos que ela recupera neste capítulo final e que traduzem perfeitamente o que vai ser tematizado nas discussões sobre ética ordinária (Das 2020a:279).

Por fim, é importante indicar, mesmo que muito superficialmente, como estas questões estão invariavelmente ligadas à própria concepção de etnografia da autora. Em mais de um momento, Das se refere a seu processo de pesquisa como se envolvesse formas de paciência crítica ou paciência política (Das 2010a, 2012b). Mais do que se remeter apenas à relevância inquestionável do tempo no processo de interlocução, o que envolve a participação em pequenas rotinas, o compartilhamento de conversas, comidas e dramas do dia a dia, parece-me que ela nos fala da importância de sustentar a incerteza como bem mais que uma etapa ou vicissitude temporária. Recorrendo uma vez mais às formulações de Wittgenstein sobre o jogo de linguagem, em especial à sua imprevisibilidade e não razoabilidade - semelhantes à vida, portanto - Das nos coloca a questão de como a formulação de nossos conceitos na antropologia, assim como a escrita de nossas experiências de campo podem e devem ser afetadas pela incerteza, esta marca primordial da textura do cotidiano (Das 2018:547).

Para além de certos recursos constantes em seu texto, como deixar marcadas hesitações e incompreensões, ou do uso refletido dos fragmentos, a que já fiz menção na parte anterior deste ensaio, o potencial da incerteza se faz presente no modo como as diferentes ordens de conversas que se cruzam em seu texto jamais estão a serviço de uma definição final (Das 2015a:373-374). Ao invés disso, nos vemos participando de um processo sempre relativamente em aberto em que a grande questão, acompanhando Cavell novamente, não seria chegar ao fim, mas habitar o meio, sustentando as condições de estar no mundo (Das 2018:548). Esta sustentação, por sua vez, depende sempre de algo que talvez não apareça com evidência em Vida e Palavras, mas que se relaciona tanto ao tema da descida ao ordinário quanto da etnografia como uma forma também de autobiografia (Das 2020a:33). Trata-se da presença de algum horizonte de futuro, sem o que o trabalho de habitar o mundo em cenários de devastação ou mesmo de grande indefinição torna-se impossível. O futuro, porém, não se traduz necessariamente em um plano ou projeto, mas talvez possa ser mais bem compreendido como decorrência do "caráter elusivo do cotidiano", esta capacidade de imaginar antes mesmo de ver que nos anima a sustentar a vida em momentos de atordoamento (Das 2018:537). 
Em meio a um ano como o que vivemos, encontrar sentido ético, político e existencial na incerteza parece-me crucial. Em um texto em que reflete sobre a pandemia da Covid-19 e, em especial, sobre seu lugar "sem esperança ou desespero", Das fala da experiência de atravessar o semestre sendo instada, junto e por estudantes, a pensar sobre o que a antropologia teria a dizer e a fazer em um momento como este (Das 2020b). Temos algo, afinal, além de críticas afiadas a oferecer? Entre os pontos levantados por ela, há menos uma resposta do que chamados de cuidado e atenção: considerar a responsabilidade que temos junto aos que são mais brutalmente atingidos pelas políticas adotadas; abrirmo-nos metodologicamente a diferentes possibilidades, inclusive no diálogo estreito com outras disciplinas; atentar para a renovada urgência de temas como a ética do cuidado e a violência doméstica, entre outros e, o que me parece mais relevante, não deixarmos de lado o amor pela "compreensão sutil e nuançada" (:03), por mais que a sofreguidão da emergência ou o afã das respostas imediatas nos interpele. Volto, por fim, à imagem do conhecimento como conectado a um gesto de espera que ela destaca no final do primeiro capítulo de Vida e Palavras. Ao contrário da inação, a espera, neste caso, indica o abrir-se à possibilidade de que o conhecimento do outro nos marque (Das 2020a:33). Cabe-nos, então, atuar sustentando este duplo registro do tempo e do ritmo, que pede atenção à angústia de um mundo que parece, uma vez mais, se desfazer aceleradamente, mas sem apagar o valor de se deixar marcar lentamente por aqueles com os quais trabalhamos e vivemos.

Recebido em 23 de novembro de 2020

Aprovado em 01 de dezembro de 2020

Adriana de R. B. Vianna

Professora do Programa de Pós Graduação em Antropologia Social do Museu Nacional, Universidade Federal do Rio de Janeiro. Desenvolve e orienta pesquisas sobre relações de gênero, violência, processos de Estado e ações coletivas.

https://orcid.org/0000-0002-5158-729X

Email: adrianavianna@mn.ufrj.br 


\section{Notas}

1 Há que se mencionar positivamente o fato de o livro nos chegar através de uma editora universitária, contando em especial com a dedicação de sua diretora, a antropóloga Cynthia Sarti. A tradução foi feita por Bruno Gambarotto e a revisão técnica, por mim.

2 Os textos já traduzidos para o português são Das 1999; Das 2007b; Das 2011; e Das 2017.

3 As coletâneas a que me refiro são: Kleinman; Das e Lock 1998; Das; Kleinman; Lock; Ramphele e Reynolds 2000; e Das; Kleinman; Lock; Ramphele e Reynolds 2001.

4 Mariza Peirano tem, sem dúvida, papel central na divulgação do trabalho de Das antes mesmo da publicação de Critical Events. Peirano inicia seu memorial, em 1992, justamente com um comentário sobre o momento em que conheceu Veena Das, em 1987, por ocasião de seu trabalho de pesquisa na Índia e de como, ao participarem de um mesmo seminário e trocarem posteriormente reminiscências sobre suas respectivas formações em um jantar na casa de Das, proximidades geracionais, pessoais e de trajetória se revelaram, apesar das diferenças igualmente presentes. (Peirano 1992. Disponível em: http://www.marizapeirano.com.br/). Usando minha própria memória como referência - justo por não ser um fato nada "individual" registro que tive contato pela primeira vez com o trabalho de Das assim que iniciei o doutorado no PPGAS/Museu Nacional, em 1997. Critical Events, que havia sido recentemente publicado, integrava a bibliografia da disciplina ministrada por Federico Neiburg com o tema "Antropologia dos Estados Nacionais e das Formas de Violência Coletiva" (MNA 801 - Problemas de Antropologia Comparada).

5 O tema das possíveis aproximações entre as antropologias brasileira e indiana é explorado com grande densidade no conhecido ensaio de Peirano para a Annual Review of Anthropology, "When Anthropology is at Home: The different contexts of a single discipline" (Peirano 1998). A conferência pode ser acessada em https://www. youtube.com/watch?v=GrXXYqJU9bo.

6 Paula Lacerda, em texto a ser publicado, defende que a própria concepção de etnografia sustentada por Das e o modo como esta se imbrica à noção de sujeito afinam-se com inquietações presentes em perspectivas decoloniais, em estudos subalternos e em tradições da antropologia brasileira (Lacerda 2018).

7 A entrevista concedida a Michel Misse, Alexandre Werneck, Patricia Birman, Pedro Paulo Pereira, Gabriel Feltran e Paulo Malvasi foi publicada originalmente na Revista Dilemas (Das 2012b) e mais recentemente republicada em inglês em Chatterji, R. (ed.) 2015a:400-412.

8 Entre os dossiês, menciono "Violência: outros olhares", organizado por Mariza Corrêa e Iara Beleli, para cadernos pagu, do qual consta inclusive o já mencionado texto de Das (Corrêa \& Beleli 2011) e "Sofrimento e Violência", organizado por Ceres Victora e Cynthia Sarti para a Horizontes Antropológicos (Victora \& Sarti 2014). O mapeamento de artigos avulsos centrados ou influenciados por seu trabalho é, 
sem dúvida, abrangente e complexo demais para ser feito nos limites deste texto. O mesmo se dá com os cursos de graduação e pós-graduação. Detenho-me, assim, em dois breves exemplos de cursos que não apenas incluem seus textos como parte da bibliografia, mas também se voltam à compreensão da obra da autora: a disciplina "Cotidiano e Rupturas - a perspectiva de Veena Das", ministrada por Ceres Victora, na UFRGS, em 2015 (https://www.ufrgs.br/ppgas/portal/paginas/programa. php?id=ANP19\&sem=2015-1) e o curso de extensão "Entre margens, violência e sofrimento: Introdução ao pensamento de Veena Das", ministrado por Carolina Parreiras na USP em 2018 (http://sce.fflch.usp.br/node/2817).

9 Sua proximidade com os escritos de Wittgenstein se dá em meados dos anos 1970, com forte impacto em sua sensibilidade do papel das diferentes vozes e suas tonalidades nas Investigações Filosóficas. É a partir dos anos 1990, porém, que o encontro com o trabalho de Cavell, em especial, e outros autores, permite, em suas palavras, "respirar com mais tranquilidade", chegando, senão a respostas precisas, à percepção das "perguntas certas a fazer" (Das 2015c:246-7).

10 Contrapondo-se à ansiedade de definir o que seja violência, Das defende que o engajamento na própria instabilidade do que seja nomeado como violência deveria nos guiar (Das 2008c:284). Este tema é retomado em mais detalhe em entrevistas que se seguiram à publicação de Life and Words, buscando sobretudo esclarecer certas associações entre violência e extraordinário, indicando o quanto o ordinário é prenhe de possibilidades de violência (Das 2010a:05), bem como para a complexidade das relações que envolvem intimidade e violência (Das 2010b:139).

11 São inúmeras as passagens em que estas pegadas de indeterminação são deixadas, dúvidas registradas e em que a sensação de não compreender plenamente o que se passa é sustentada no texto. Não fazendo sentido tentar recuperá-las em quantidade, deixo duas indicações aqui que considero preciosas. A primeira delas está em uma passagem de um de seus textos sobre ética ordinária, posteriores a Vida e Palavras. Após reagir a certas críticas sobre seu modo de fazer antropologia como marcado pela prática de deixar que as histórias emerjam em pedaços, ela defende que é preciso manter a presença da indeterminação e da incerteza no texto (Das 2015b:20). A segunda está no modo como decide dialogar com os textos escritos por outra geração de antropólogos influenciados por seu trabalho, oferecendo como contrapartida a releitura de um antigo extrato de diário de campo, no qual a pluralidade de conversas, afetos, angústias e motivações se revela com especial força (Das 2015a).

12 Esta discussão é feita sobretudo no capítulo 5. Como coloca ela, "O trabalho do tempo, não sua imagem ou representação, é o que me importa aqui enquanto descrevo esses processos" (Das 2020:109).

13 Este tema é retomado também em Das (2012 e 2015a).

14 A noção de "exercícios espirituais" é formulada por Hadot para indicar o engajamento na Grécia Antiga à filosofia como um modo de vida e de elevação. O potencial escandaloso de sua construção residiria, desse modo, justo na correlação entre os exercícios espirituais e o trabalho feito em meio à vida ordinária para, igualmente, cultivar um modo de vida (Das 2012, 2015a, 2015b). 


\section{Errata}

Este artigo foi publicado na seção incorreta. Na página 1:

Onde se lia:

ARTIGO

Leia-se:

ENSAIO BIBLIOGRÁFICO

\section{Referências bibliográficas}

AUSTIN, J. L. 1962. How to do things with words. Cambridge, MA: Harvard University Press.

CHATTERJI, Roma . 2015 . "Conversations, Generations, Genres: Anthropological Knowing as a Form of Life". In: R. Chatterji (ed.), Wording the World. Veena Das and Scenes of Inheritance. New York: Fordham University Press. pp. 01-20. CORRÊA, Mariza \& BELELI, Iara. 2011. "Apresentação. Dossiê Violência: Outros Olhares". cadernos pagu, 37:7-8.

DAS, Veena. 1995. Critical Events: An Anthropological Perspective on Contemporary India. New Delhi: Oxford University Press. . 1999. "Fronteiras, violência e o trabalho do tempo: alguns temas wittgensteinianos". Revista Brasileira de Ciências Sociais, v. 14, n. 40:31-42. . 2007a. Life and Words: violence and the descente into the ordinary. Berkeley, Los Angeles; London: University of Califiornia Press. . 2007b. "Violência e Tradução". Revista Brasileira de Sociologia da Emoção, 6 (18):623-636.

. 2008a. Sujetos de dolor, agentes de dignidad. Ed. Francisco A. Ortega. Bogotá: Universidad Nacional de Colombia, Facultad de Ciencias Humanas; Pontificia Univesidad
Javeriana; Instituto Pensar. . 2008b. "El estado y sus márgenes. Etnografías comparadas". Cuadernos de Antropología Social, n. 27:19-52. . 2008c. "Violence, gender and subjectivity". Annual Review of Anthropology, 37:283-299. . 2010c. "Engaging the life of the other: love and everyday life". In: M. Lambek (ed.), Ordinary Ethics. Anthropology, language and action. New York: Fordham University Press. pp. 376-398.

. 2011. "O ato de testemunhar: violência, gênero e subjetividade". cadernos pagu, 37:9-41. . 2012. "Ordinary ethics". In: D. Fassin (ed.), A Companion to Moral Anthropology. Oxford: BlackwellWiley. pp. 133-149. . 2015a. "Adjacent Thinking: A Postscript". In: R. Chatterji (ed.), Wording the World. Veena Das and Scenes of Inheritance. New York: Fordham University Press. pp. 372399. . 2015b. "Lecture Two: What does ordinary ethics look like?". In: M. Lambek; V. Das; D. Fassin \& W. Keane (eds.), Four Lectures on Ethics: Anthropological Perspectives. Chicago: Hau Books/ University of Chicago Press. . 2015c. "A life in books". Journal of 
the Royal Anthropological Institute, n. 21:246-250.

. 2015d. Affliction: Health, Disease, Poverty. New York: Fordham University Press. . 2017. "Corrupção e possibilidade da vida". Repocs, v. 14, n. 27:131-148. . 2018. "Ethics, self-knowledge, and life taken as a whole". HAU: Journal of Ethnographic Theory, 8 (3):537-549 . 2020a. Vida e Palavras. A Violência e sua Descida ao Ordinário. São Paulo: Editora da Unifesp. . 2020b. "Encarando a Covid-19: Meu lugar sem esperança ou desespero". Dilemas: Revista de Estudos de Conflito e Controle Social - Reflexões na Pandemia, Texto 26. pp. 01-08.

DAS, Veena \& POOLE, Deborah (eds). 2004. Anthropology in the Margins of the State. Santa Fé/Délhi: SAR Press/ Oxford University Press.

DAS, V.; KLEINMAN, A.; RAMPHELE, M. \& REYNOLDS, P. (eds). 2000. Violence and Subjectivity. Berkeley/ Los Angeles/London: University of California Press.

DAS, V.; KLEINMAN, A.; LOCK, M.; RAMPHELE, M. \& REYNOLDS, P. (eds). 2001. Remaking a World: Violence, Social Suffering and Recovery. Berkeley/Los Angeles/ London: University of California

\section{Entrevistas}

DAS, Veena. 2010a. On life and Words: an interview with Veena Das by Asli Zengin. Feminist Approaches in Culture and Politics, v. 10:1-15.

DAS, Veena. 2010b. Listening to voices: an interview with Veena Das. Kim Turcot DiFruscia. Alterités, v. 7, n. 1:136-145.

DAS, Veena. 2012b. Entre palavras
Press.

KLEINMAN, A.; DAS, V. \& LOCK, M. (eds.) 1998. Social suffering. Berkeley: University of California Press.

LACERDA, Paula. 2018. "Veena Das: conceitos e propostas". mimeo.

LAMBEK, Michael. 2010. "Introduction". In: M. Lambek (ed.), Ordinary Ethics. Anthropology, language and action. New York: Fordham University Press. pp. 1-37.

PEIRANO, Mariza. 1992. "Não foi por acaso: um depoimento". Disponível em: http://www.marizapeirano.com. br.

1998. "When anthropology is at home: the different contexts of a single discipline". Annual Review of Anthropology, v. 27:105-129.

PEREIRA, Pedro Paulo. 2010. "Violência, gênero e cotidiano: o trabalho de Veena Das". cadernos pagu, 35:357369.

VICTORA, Ceres \& SARTI, Cynthia. 2014. "Apresentação - Dossiê Sofrimento e Violência". Horizontes Antropológicos, 42:9-18.

VIEIRA, Suzane. 2010. "Resenha: Das, Veena. 2007. Life and Words: violence and the descent into the ordinary". Mana: Estudos de Antropologia social, v. 16 (2):517-520.

e vidas: Um pensamento de encontro com margens, violências e sofrimentos. Entrevista com Veena Das. Michel Misse, Alexandre Werneck, Patricia Birman, Pedro Paulo Pereira, Gabriel Feltran, Paulo Malvasi. Dilemas: Revista de Estudos de Conflito e Controle Social, v. 5, n. 2:335-356. 
VIDA, PALAVRAS E ALGUNS

OUTROS TRAÇADOS:

LENDO VEENA DAS

\section{Resumo}

O ensaio parte da publicação em português do livro Vida e Palavras: A Violência e sua Descida ao Ordinário, de Veena Das, para discutir alguns elementos de sua obra que têm impactado a antropologia no Brasil. Em um primeiro momento, discorre sobre a recepção de seu trabalho desde meados dos anos 1990 no Brasil, para, em seguida, oferecer uma leitura sobre Vida e Palavras. Em sua última parte, o ensaio busca conectar reflexões sobre ética e etnografia presentes no livro com alguns textos posteriores da autora, sublinhando em especial a noção de ética ordinária.

Palavras chave: Veena Das; Vida e Palavras; ética ordinária; etnografia.
LIFE, WORDS AND OTHER WEFTS: READING VEENA DAS

\section{Abstract}

Starting from the publication of the Portuguese translation of Veena Das's Life and Words: Violence and the Descent into the Ordinary (Vida e Palavras: A Violência e sua Descida ao Ordinário), this essay discusses certain aspects of that book which have had an impact on anthropology in Brazil. First it traces the reception of her work in Brazil during the 1990s, and then provides an interpretation of Life and Words. Finally, the essay seeks to connect the reflections on ethics and ethnography presented in the book with some of the author's posterior work, focusing specifically on the notion of ordinary ethics.

Key Words: Veena Das; Life and Words; Ordinary ethics; Ethnography. 


\section{VIDA, PALABRAS Y ALGUNOS}

OTROS TRAZADOS:

\section{LEYENDO VEENA DAS}

\section{Resumen}

El ensayo parte de la publicación en portugués de libro Vida e Palavras: A Violência e sua Descida ao Ordinário, de Veena Das, para discutir algunos elementos de su obra que han impactado la antropología en Brasil. En un primer momento, discurre sobre la recepción de su trabajo desde mediados de la década de 1990 en Brasil, luego ofrece una lectura sobre Vida e Palavras. En su última parte, el ensayo busca conectar reflexiones sobre ética y etnografía presentes en el libro con algunos textos posteriores de la autora, recalcando en especial la noción de ética ordinaria.

Palavras clave: Veena Das; Vida y Palabras; ética ordinaria, etnografía. 